\title{
Pharmacokinetic Study and Limited Sampling Strategy of Cyclosporine in Japanese Heart Transplant Recipients
}

\author{
Kyoichi Wada, BS; Mitsutaka Takada, PhD**; Takashi Ueda, BS ${ }^{\dagger}$; Hiroyuki Ochi, BS; \\ Hideki Morishita, BS; Akihisa Hanatani, MD*; Takeshi Nakatani, MD*
}

\begin{abstract}
Background The purpose of this study was to characterize the pharmacokinetics of cyclosporine (CsA) in Japanese heart transplant patients, and to optimise the monitoring strategy based on measurements of the area under the curve of plasma concentration absorption phase or $2 \mathrm{~h}$ post-dose concentrations $\left(\mathrm{C}_{2}\right)$.

Methods and Results At defined time periods during the first year after transplantation, the area under the curve for the CsA serum concentration from 0 to $4 \mathrm{~h}\left(\mathrm{AUC}_{0}-4 \mathrm{~h}\right)$ was evaluated. Pharmacokinetic parameters and renal function at 1 month and 12 months after transplantation were compared in 7 Japanese patients. The highest coefficient of determination between CsA AUC $0-4 \mathrm{~h}$ and a single concentration was observed using $\mathrm{C}_{2}\left(\mathrm{r}^{2}=0.838\right)$. For CsA pharmacokinetics, the mean measurement of whole blood trough levels value at 12 months was significantly lower than at 1 month after transplantation $(\mathrm{p}=0.026)$. The mean serum creatinine level at 12 months was significantly higher than at 1 month $(1.00 \mathrm{mg} / \mathrm{dl}$ vs $0.73 \mathrm{p}=0.0194)$.

Conclusion A single-time-point model that includes $\mathrm{C}_{2}$ is useful for predicting $\mathrm{CsA}$ AUC0-4 $\mathrm{h}$ in Japanese heart transplant patients. Mean $\mathrm{C}_{2}$ values $>1,000 \mathrm{ng} / \mathrm{ml}$ were obtained in patients with no rejection at 1 month and 12 months after transplantation; however, renal impairment may occur. (Circ J 2006; 70: 1307-1311)
\end{abstract}

Key Words: $\mathrm{C}_{2}$ monitoring; Cyclosporine; Heart; Pharmacokinetics; Transplantation

C yclosporine (CsA) microemulsion $\left(\mathrm{Neoral}^{\circledR}\right)$ is widely used in solid organ transplantation, but it has side-effects, including hypertension and nephrotoxicity. Therapeutic drug monitoring (TDM) based on the measurement of whole blood trough levels $\left(\mathrm{C}_{0}\right)$ has been used to prevent these side-effects, but despite monitoring, the incidence of end-stage renal disease requiring renal replacement therapy after heart transplantation ranges between 1.0 and $8.0 \%$ ! Recently, use of full area under the curve (AUC) analysis was demonstrated to be a precise predictor of acute rejection and graft survival? Following oral administration, CsA is rapidly and completely absorbed during the first $4 \mathrm{~h}$. Absorption profiling is needed as a better monitoring strategy ${ }^{3-7}$ In renal transplant patients, the AUC during the absorption phase ( $\mathrm{AUC}_{0}-4 \mathrm{~h}$ ) highly correlates to the full AUC and has been shown to be a better marker for rejection and nephrotoxicity than $\mathrm{C} 04$ In addition, the $2 \mathrm{~h}$ post-dose concentration $\left(\mathrm{C}_{2}\right)$ was shown to be the best single time point to be the most accurate surrogate marker for $\mathrm{AUC}_{0}-4 \mathrm{~h}$ and $\mathrm{C}_{2}$ was found to be a better marker for rejection and nephrotoxicity than $\mathrm{C}_{0}^{3,4}$ Cantarovich et al demonstrated a clinical benefit in long-term heart transplant patients monitored with $\mathrm{C}_{2}$ compared to $\mathrm{C}_{0}^{5,8}$ and other groups have reported a clinical benefit of $\mathrm{C}_{2}$ monitoring in heart transplant patients., 10 Moreover, $\mathrm{C}_{2}$ has been

(Received May 11, 2006; revised manuscript received August 1, 2006; accepted August 4, 2006)

Departments of Pharmacy, *Organ Transplantation, National Cardiovascular Center, Suita, **Division of Practical Pharmacy, School of Pharmaceutical Sciences, Kinki University, Osakasayama and Department of Biochemistry and Molecular Biology, Kyoto Pharmaceutical University, Kyoto, Japan

Mailing address: Kyoichi Wada, BS, Department of Pharmacy, National Cardiovascular Center, 5-7-1 Fujishirodai, Suita 565-0873,

Japan. E-mail: kwada@hsp.ncvc.go.jp reported to correlate with the maximal inhibition of calcineurin ${ }^{11}$ and the maximal inhibition of interleukin-2 production! 12,13

The pharmacokinetics of CsA in Japanese renal transplant patients has been previously reported, ${ }^{14}$ but not in Japanese heart transplant patients, which was the purpose of this study by compare the monitoring strategies of measuring $\mathrm{AUC} 0-4 \mathrm{~h}$ or $\mathrm{C}_{2}$.

\section{Methods}

\section{Patients and Medications}

Seven Japanese patients were enrolled (6 with dilated cardiomyopathy, 1 with dilated phase of hypertrophic cardiomyopathy as the primary disease). They had undergone heart transplantation at the National Cardiovascular Center, Japan between July 2000 and February 2004. All patients received standard triple-drug immunosuppression with CsA, mycophenolate mofetil (MMF) and prednisone. Pharmacokinetics profiles were obtained from the patients during the first 12 months after transplantation. None of the subjects took no concurrent medications that interfered with CsA pharmacokinetics, such as macrolides or calciumchannel blockers. However, fluconazole was administered to all patients during the first 12 months after transplantation. CsA (Neoral ${ }^{\circledR}$, Novartis Pharma K.K., Tokyo, Japan) was initially administered at a dose of $6 \mathrm{mg} \cdot \mathrm{kg}^{-1} \cdot \mathrm{day}^{-1}$ in 2 divided doses. Thereafter, the dose was adjusted to achieve trough levels of $350-450 \mathrm{ng} / \mathrm{ml}$ during the first month, $250-350 \mathrm{ng} / \mathrm{ml}$ at $2-3$ months, $200-300 \mathrm{ng} / \mathrm{ml}$ at 4-12 months and $100-250 \mathrm{ng} / \mathrm{ml}$ at 13 or more months after transplantation. In addition, the dose of CsA was adjusted based on the AUC during hospital admission for periodic biopsy. MMF (Cellcept, Chugai Pharma K.K., Tokyo, Japan) was initially administered at a dose of $1 \mathrm{~g}$ in 
Table 1 Characteristics of Study Patients

\begin{tabular}{lc}
\hline \hline No. of patients & 7 \\
Gender $(M / F)$ & $6 / 1$ \\
Age at heart transplantation (years)* & $33.1 \pm 11.8(14-46)$ \\
Primary disease (dilated cardiomyopathy/dilated phase of hypertrophic cardiomyopathy) & $6 / 1$ \\
No. of patients with incidence of ISHLT rejection Grade 3a within 1 year & 1 \\
\hline
\end{tabular}

ISHLT, International Society for Heart and Lung Transplantation. *Mean $\pm S D$ (range).

Table 2 Correlation of 1-Point, 2-Point, and 3-Point Estimated AUC0-4h With Actual AUC (n=45)

\begin{tabular}{|c|c|c|c|c|c|c|c|}
\hline \multirow{2}{*}{ Model } & \multirow{2}{*}{$\begin{array}{l}\text { Sampling } \\
\text { times, } h\end{array}$} & \multirow{2}{*}{ Model equation } & \multirow{2}{*}{$r_{2}$} & \multicolumn{4}{|c|}{ Prediction error (\%) } \\
\hline & & & & Mean $\pm S D$ & Within $\pm 15 \%$ & $<-15 \%$ & $>15 \%$ \\
\hline 1 & 0 & $5.95 C 0+1,598.93$ & 0.258 & $5.31 \pm 24.77$ & $24(53.3)$ & $10(22.2)$ & $11(24.4)$ \\
\hline 2 & 1 & $1.56 C_{1}+1,983.71$ & 0.808 & $1.51 \pm 11.86$ & $37(82.2)$ & $3(6.7)$ & $5(11.1)$ \\
\hline 3 & 2 & $2.46 C_{2}+769.49$ & 0.838 & $0.76 \pm 10.74$ & $41(91.1)$ & $2(4.4)$ & $2(4.4)$ \\
\hline 4 & 4 & $-0.77 C_{4}+3,973.74$ & 0.028 & $6.81 \pm 27.81$ & $18(40.0)$ & $11(24.4)$ & $16(35.6)$ \\
\hline 5 & 0,1 & $2.68 C 0+1.43 C_{1}+1,286.64$ & 0.854 & $1.20 \pm 10.10$ & $38(84.4)$ & $3(6.7)$ & $4(8.9)$ \\
\hline 6 & 0,2 & $2.07 C 0+2.27 C_{2}+334.42$ & 0.865 & $0.60 \pm 9.70$ & $40(88.9)$ & $2(4.4)$ & $3(6.7)$ \\
\hline 7 & 0,4 & $6.85 C 0-1.43 C_{4}+2,346.00$ & 0.349 & $4.50 \pm 22.30$ & $21(46.7)$ & $10(22.2)$ & $14(31.1)$ \\
\hline 8 & 1,2 & $0.85 C_{1}+1.49 C_{2}+1,027.98$ & 0.950 & $0.20 \pm 7.00$ & $43(95.6)$ & $1(2.2)$ & $1(2.2)$ \\
\hline 9 & 1,4 & $1.72 C_{1}+1.08 C_{4}+1,059.56$ & 0.854 & $1.30 \pm 11.20$ & $39(86.7)$ & $4(8.9)$ & $2(4.4)$ \\
\hline 10 & 2,4 & $2.54 C_{2}+0.51 C_{4}+309.71$ & 0.849 & $0.70 \pm 9.60$ & $40(88.9)$ & $2(4.4)$ & $3(6.7)$ \\
\hline 11 & $0,1,2$ & $1.72 C_{0}+0.83 C_{1}+1.37 C_{2}+657.43$ & 0.968 & $0.10 \pm 5.57$ & $44(97.8)$ & $1(2.2)$ & $0(0)$ \\
\hline 12 & $0,1,4$ & $1.85 C_{0}+1.58 C_{1}+0.74 C_{4}+862.81$ & 0.872 & $1.16 \pm 10.09$ & $39(86.7)$ & $2(4.4)$ & $4(8.9)$ \\
\hline 13 & $0,2,4$ & $1.82 C_{0}+2.33 C_{2}+0.23 C_{4}+181.18$ & 0.866 & $0.62 \pm 9.35$ & $41(91.1)$ & $2(4.4)$ & $2(4.4)$ \\
\hline 14 & $1,2,4$ & $1.02 C_{1}+1.48 C_{2}+1.07 C_{4}+114.72$ & 0.995 & $0.02 \pm 2.43$ & $45(100)$ & $0(0)$ & $0(0)$ \\
\hline
\end{tabular}

$A U C 0-4 h$, area under the curve $(A U C)$ for the cyclosporine serum concentration from 0 to $4 \mathrm{~h}$; $C$, measurement of whole blood trough levels; $C_{1}, 1$ h post-dose concentrations; $C_{2}, 2$ h post-dose concentrations; $C_{4}, 4$ h post-dose concentrations.

2 divided doses, and finally $2-3 \mathrm{~g}$ for maintenance in accordance with the leukocyte count. Subsequent doses of MMF were adjusted based on the AUC of mycophenolic acid during the admission for scheduled biopsy. A standard prednisone taper was carried out in all patients in accordance with the protocol of the National Cardiovascular Center ${ }^{15}$

The surveillance protocol of the National Cardiovascular Center following heart transplantation consists of an endomyocardial biopsy once weekly for the first 3 weeks, then $5^{\text {th }}, 7^{\text {th }}, 11^{\text {th }}$, and $18^{\text {th }}$ weeks. After 6 months, biopsies are performed every 6 months during the first year. After the first year, biopsies are performed every 6 months for the next 5 years, and then at 12 month intervals thereafter. In this study Grade 3a rejection or above according to the criteria of the International Society for Heart and Lung Transplantation (ISHLT) was considered as rejection. All research procedures were conducted according to the institute's clinical research guidelines and all patients gave written informed consent for disclosure of their clinical data.

\section{TDM and Pharmacokinetic Profiles}

Pharmacokinetic profiles were obtained from the 7 patients during periodic hospital admissions for biopsy within the 12 months after transplantation. The plasma concentration of CsA was measured by fluorescence polarization immunoassay (TDx, Abbott Japan Co, Ltd). We collected a blood sample from the patients before taking CsA and 1,2, 4,6 , and $12 \mathrm{~h}$ after dosing. Approximately $1 \mathrm{ml}$ of venous blood was collected each time into a disposable syringe and transferred to a vacuum blood collection tube. The samples were centrifuged, and harvested serum was frozen at $-30^{\circ} \mathrm{C}$ until analysis.

\section{Limited Sampling Strategy (LSS) Development}

We searched for predictive models of CsA AUC0-4h using multiple regression analysis. The CsA $\mathrm{AUC}_{0}-4 \mathrm{~h}$ values were calculated by trapezoidal approximation. These analyses produced equations of the form, $\mathrm{AUC}=\mathrm{a}_{1} \mathrm{C}_{1} \ldots+\mathrm{an}_{n} \mathrm{C}_{n}+$ $\mathrm{b}$, where $\mathrm{an}$ and $\mathrm{b}$ are coefficients and $\mathrm{n}$ is the number of samples $(\mathrm{n} \leq 3)$. Data were analyzed using Statcel 2 (Excel, Visual Basic for Applications for Windows.

\section{Statistical Analysis of Pharmacokinetic Data and Renal Function}

Pharmacokinetic parameters at 1 month (34-49 days) and 12 months (358-377 days) after transplantation were calculated in the 7 patients. One patient had 2 pharmacokinetic profiles calculated at 12 months after transplantation because of rejection. Rejection data was excluded and a total of 14 profiles without rejection were used for the analyses. The time to maximum concentration $\left(t_{\max }\right), \mathrm{C}_{0}$ and $\mathrm{C}_{2}$ were derived directly from the measured values. Data are expressed as mean $\pm \mathrm{SD}$. The mean $\pm \mathrm{SD}$ for Dose, $\mathrm{AUC}_{0}-4 \mathrm{~h}, \mathrm{AUC}_{0}-4 \mathrm{~h} / \mathrm{Dose}, \mathrm{C}_{0}, \mathrm{C}_{2}$, tmax and renal function were compared using Student's t-test. Statistical significance was defined if the null hypothesis could be rejected at the $\mathrm{p}<0.05$ level.

\section{Results}

Patient Characteristics (Table 1)

A total of 7 patients were evaluated (6 males, 1 female; mean age $\pm \mathrm{SD}, 33.1 \pm 11.8$ years, range $14-46$ years) (Table 1). One of them experienced ISHLT Grade 3a rejection at 6 and 12 months after transplantation.

LSS

Forty-five pharmacokinetic profiles were obtained from 

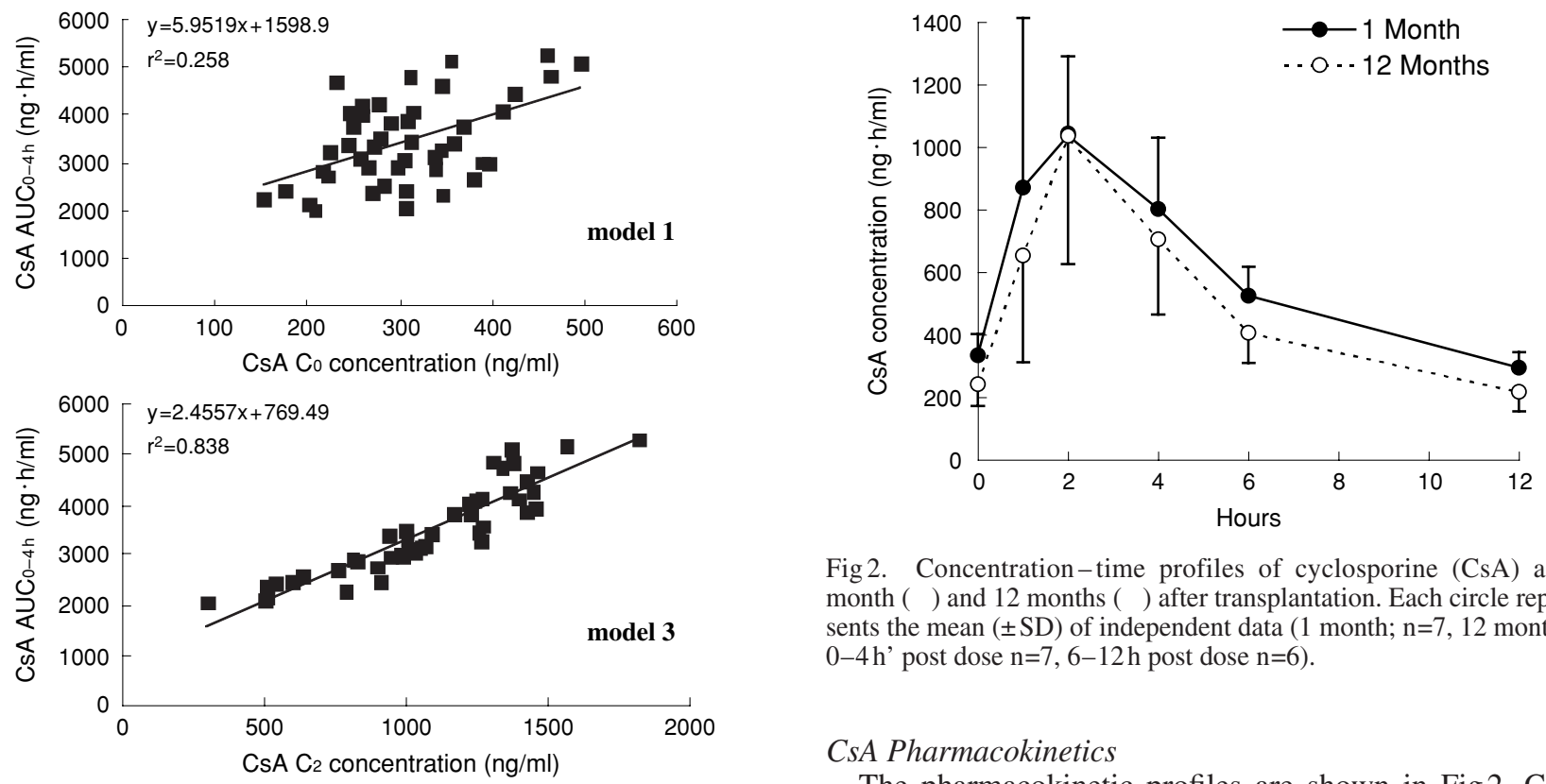

Fig 2. Concentration-time profiles of cyclosporine (CsA) at 1 month $(\bigcirc)$ and 12 months $(\bigcirc)$ after transplantation. Each circle represents the mean $( \pm \mathrm{SD})$ of independent data (1 month; $n=7,12$ months; $0-4 h$ ' post dose $n=7,6-12 h$ post dose $n=6$ ).

\section{CsA Pharmacokinetics}

The pharmacokinetic profiles are shown in Fig 2. CsA

Fig 1. Correlation analysis graphs for $\mathrm{C}_{0}$ and $\mathrm{C}_{2}$ with $\mathrm{AUC}_{0}-4 \mathrm{~h}$. $\mathrm{Cs}_{\mathrm{A}} \mathrm{A}$, cyclosporine; $\mathrm{AUC}_{0}-4 \mathrm{~h}$, area under the curve during the absorption phase; $\mathrm{C}_{0}$, measurement of whole blood trough levels; $\mathrm{C}_{2}, 2 \mathrm{~h}$ postdose concentration.

the 7 patients during the first 12 months after transplantation. The correlations between CsA concentrations at the time points and $\mathrm{CsA} \mathrm{AUC}_{0}-4 \mathrm{~h}$ values and prediction errors for the abbreviated $\mathrm{AUC}_{0}-4 \mathrm{~h}$ profiles are summarized in Table 2. Fourteen models were developed and analyzed for their ability to estimate the CsA AUC0-4h. The best model for predicting the $\mathrm{CsA} \mathrm{AUC}_{0-4 \mathrm{~h}}$ was a 3-time-point model (model 14: $\mathrm{C}_{1}, \mathrm{C}_{2}, \mathrm{C}_{4} ; \mathrm{r}^{2}=0.995$ ) with a mean prediction error of $0.02 \pm 2.43 \%$. The estimated prediction errors fell within $\pm 15 \%$ in $100 \%$ of the profiles $(45 / 45)$ using this model. The 2-sample model that gave the best $\mathrm{r}^{2}$ value $(0.95)$ was model $8\left(\mathrm{C}_{1}, \mathrm{C}_{2}\right)$ with a mean prediction error of $0.20 \pm 7.00 \%$. Using this model, $95.6 \%$ profiles (43/45) had an estimated prediction error within $\pm 15 \%$. The highest coefficient of determination between the $\mathrm{CsA} \mathrm{AUC}_{0}-4 \mathrm{~h}$ and a single concentration was observed with $\mathrm{C}_{2}\left(\mathrm{r}^{2}=0.838\right)$ with a mean prediction error of $0.76 \pm 10.7 \%$. Using this model, $91.1 \%$ profiles $(41 / 45)$ had an estimated prediction error within $\pm 15 \%$. Co poorly correlated with CsA $\mathrm{AUC}_{0}-4 \mathrm{~h}$ values with an $\mathrm{r}^{2}$ value of 0.258 (Fig 1). Using this method, the mean prediction error was $5.31 \pm 24.77 \%$ and the estimated prediction error fell within $\pm 15 \%$ in only $53.3 \%$ of the profiles (24/45). absorption varied more widely between patients during the first $4 \mathrm{~h}$ post dose. The pharmacokinetic parameters of CsA at 1 month and 12 months after transplantation are presented in Table 3. The mean dose at 1 month and 12 months was 3.83 and $4.95 \mathrm{mg} \cdot \mathrm{kg}^{-1} \cdot \mathrm{day}^{-1}$, respectively. The mean $\mathrm{AUC}_{0}-4 \mathrm{~h}$ value was $3,399.46$ and $3,027.39 \mathrm{ng} \cdot \mathrm{h} / \mathrm{ml}$, respectively, and the mean AUC0-4h/Dose was 447.80 and $328.12 \mathrm{ng} \cdot \mathrm{h}^{-1} \cdot \mathrm{ml}^{-1} \cdot \mathrm{mg}^{-1} \cdot \mathrm{kg}^{-1} \cdot \mathrm{day}^{-1}$, respectively. The mean $\mathrm{C}_{0}$ was 336.20 and $242.60 \mathrm{ng} / \mathrm{ml}$, respectively and the mean $\mathrm{C}_{2}$ was $1,036.86$ and $1,029.97 \mathrm{ng} / \mathrm{ml}$, respectively. There was no significant difference in the mean doses of CsA, mean $\mathrm{AUC}_{0}-4 \mathrm{~h}$ values, mean $\mathrm{AUC}_{0}-4 \mathrm{~h} /$ Dose values, $\mathrm{C}_{2}$ values and tmax values between about 1 month and 12 months after transplantation. However, the mean $\mathrm{C}_{0}$ value at about 12 months was significantly lower than at 1 month after transplantation $(p=0.026)$. The mean serum creatinine (Scr) level at 12 months was significantly higher than at 1 month $(1.00 \mathrm{mg} / \mathrm{dl}$ vs $0.73 \mathrm{p}=0.0194)$ (Fig 3$)$. One patient developed rejection with lower $\mathrm{C}_{2}$ values $(607.2 \mathrm{ng} / \mathrm{ml})$ and lower AUC0-4h values $(2,407.9 \mathrm{ng} \cdot \mathrm{h} / \mathrm{ml})$ at 12 months after transplantation. The pharmacokinetic profiles in the patients with rejection at 6 months after transplantation were not measured.

\section{Discussion}

The present study of Japanese heart transplant patients demonstrated that a single-time-point model including $\mathrm{C}_{2}$

Table 3 Pharmakocinetic Parameters for CsA in Heart Transplant Patients Without Rejection (n=7)

\begin{tabular}{|c|c|c|c|}
\hline \multirow[b]{2}{*}{ Parameters } & \multicolumn{2}{|c|}{ After transplantation day } & \multirow[b]{2}{*}{$p$ value } \\
\hline & $\begin{array}{c}1 \text { month (34-49 days) } \\
\text { Mean }\end{array}$ & $\begin{array}{c}12 \text { months (358-377 days) } \\
\text { Mean }\end{array}$ & \\
\hline Dose $\left(\mathrm{mg} \cdot \mathrm{kg}^{-1} \cdot \mathrm{day}^{-1}\right)$ & $3.83 \pm 0.63$ & $4.95 \pm 1.96$ & 0.12 \\
\hline$A U C 0-4 h(n g \cdot h / m l)$ & $3,399.46 \pm 818.48$ & $3,027.39 \pm 875.72$ & 0.43 \\
\hline AUC0-4h/Dose $\left(\mathrm{ng} \cdot \mathrm{h}^{-1} \cdot \mathrm{ml}^{-1} \cdot \mathrm{kg}^{-1} \cdot \mathrm{day}^{-1}\right)$ & $447.80 \pm 107.64$ & $328.12 \pm 100.24$ & 0.052 \\
\hline$C_{0}(n g / m l)$ & $336.20 \pm 67.41$ & $242.60 \pm 70.06$ & 0.026 \\
\hline $\mathrm{C}_{2}(\mathrm{ng} / \mathrm{ml})$ & $1,036.86 \pm 256.15$ & $1,029.97 \pm 401.81$ & 0.97 \\
\hline$T_{\max }(h)$ & $2.29 \pm 1.25$ & $2.29 \pm 0.76$ & 0.5 \\
\hline
\end{tabular}

CsA, cyclosporine; Tmax, time to maximum concentration. Other abbreviations see in Table 2. Values are expresssed as mean $\pm S D$. 


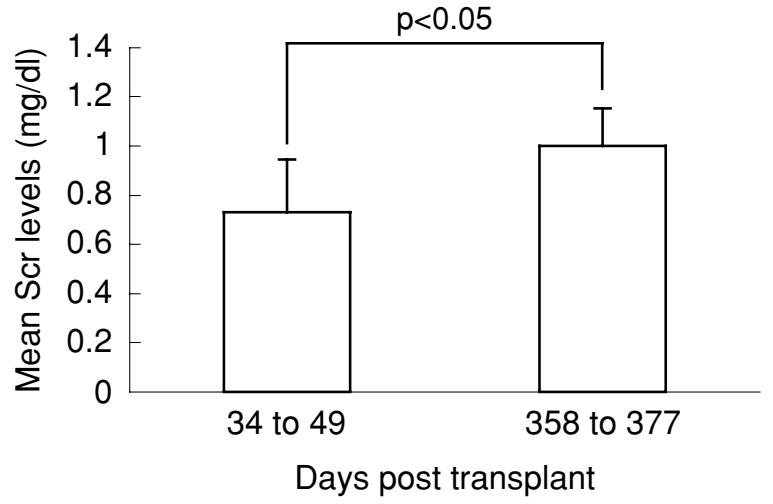

Fig 3. Mean serum creatinine (Scr) levels at 1 month (34-49 days) and 12 months (358-377 days) after transplantation.

was useful for predicting the full $\mathrm{CsA} \mathrm{AUC}_{0}-4 \mathrm{~h}$ in patients treated with MMF and prednisone concomitantly. Several pharmacokinetic studies of CsA in heart transplant patients have been reported, $1,5,7-10,13,16$ but not in Japanese patients. It has been reported that the $\mathrm{AUC}_{0-4} \mathrm{~h}$ of $\mathrm{CsA}$ is significantly associated with post transplant clinical events, but the measurement of CsA AUC0-4h using a full set of samples requires considerable personnel time, laboratory resources and quantities of the patient's blood. To support TDM of CsA in clinical practice, LSS should be developed. In the present study, the highest coefficient of determination observed was between $\mathrm{CsA}_{\mathrm{AUC}} \mathrm{A}_{-4} \mathrm{~h}$ and $\mathrm{C}_{2}$. Using this model, $91.1 \%$ of profiles had an estimated prediction error within $\pm 15 \%$. Cantarovich et al demonstrated that a singletime-point model that included $\mathrm{C}_{2}$ is the best model for predicting the $\mathrm{CsA} \mathrm{AUC}_{0}-4 \mathrm{~h}$ in stable post-heart transplant patients at 1 year or more? Arizon del Prado et al reported that a single-time-point model that included $\mathrm{C}_{2}$ is the best model for predicting the $\mathrm{CsA} \mathrm{AUC}_{0-4} \mathrm{~h}$ in post-heart transplant patients during the first month or after 1 month. ${ }^{17}$ The present study also demonstrated that a single-time-point model including $\mathrm{C}_{2}$ is the best model for predicting the CsA $\mathrm{AUC}_{0}-4 \mathrm{~h}$ in the early stage of post-heart transplantation.

It is well known that there are many medications that interfere with CsA pharmacokinetics, such as macrolides, calcium-channel blockers, and azole antifungal drugs. In the present study, all patients were co-administered fluconazole during the study period. It has been reported that $\mathrm{C}_{2}$ significantly correlates with $\mathrm{AUC}_{0}-5 \mathrm{~h}$ when ketoconazole is co-administered, ${ }^{16}$ so would be expected that the use of fluconazole should not affect the correlation between $\mathrm{AUC}_{0}-4 \mathrm{~h}$ and $\mathrm{C}_{2}$.

In the present study, the mean dose at 12 months after transplantation tended to be higher than at 1 month; however, no significant differences were observed in the mean AUC $0-4 \mathrm{~h}$ values between 1 month and 12 months post transplantation. As a result, the mean $\mathrm{AUC}_{0}-4 \mathrm{~h} /$ Dose tended to decrease at 12 months after transplantation, which suggests that clearance of CsA increases with time. It is well known that patients with severe heart failure have the potential for general decreased total body clearance, including hepatic clearance as well as renal clearance ${ }^{18,19}$ It has been reported that heart function affects pharmacokinetic parameters for some drugs ${ }^{20,21}$ The patients in this study had severe heart failure prior to transplantation, thus in the early stages postheart transplantation patients may potentially have decreased total body clearance, but which subsequently in- creases with time. Further studies are needed to investigate this issue.

Cantarovich et al studied the impact of $\mathrm{C}_{2}$ monitoring on de novo adult heart transplant patients receiving thymoglobulin (antithymocyte globulin)! The $\mathrm{C}_{2}$ target levels of their study were: $0-3$ months, $600-800 \mathrm{ng} / \mathrm{ml}$; 4-6 months, $500-700 \mathrm{ng} / \mathrm{ml} ;>6$ months, $400-600 \mathrm{ng} / \mathrm{ml}$. They reported that the mean $\mathrm{C}_{2}$ at 1 month and 12 months was $809 \pm 160$ and $616 \pm 221 \mathrm{ng} / \mathrm{ml}$, respectively. Delgado et al reported that high $\mathrm{C}_{2}$ values are associated with fewer episodes of acute cellular rejection in post-heart transplant patients? The mean $\mathrm{C}_{2}$ values of their study with no rejection were: $3-6$ months post-heart transplantation $1,403 \pm 285 \mathrm{ng} / \mathrm{ml}$, and 6-12 months post-heart transplantation $1,175 \pm 215 \mathrm{ng} / \mathrm{ml}$. The $\mathrm{C}_{2}$ values in their study were higher than those reported by other heart transplant groups. It was reported that acute cellular rejection should be suspected when the $\mathrm{C}_{2}$ value is below $600 \mathrm{ng} / \mathrm{ml}^{5,10} \mathrm{In}$ the present study, although the mean $\mathrm{C}_{0}$ values significantly decreased, no significant differences were observed in the mean $\mathrm{C}_{2}$ values between 1 month and 12 months after transplantation. Mean $\mathrm{C}_{2}$ values $>1,000 \mathrm{ng} / \mathrm{ml}$ were obtained in patients with no rejection at 1 month and 12 months after transplantation. In the case of rejection developing at 12 months after transplantation, a lower $\mathrm{C}_{2}$ value $(607.2 \mathrm{ng} / \mathrm{ml})$ was observed, which suggests that a lower $\mathrm{C}_{2}$ value is associated with an increased risk of rejection.

Cantarovich et al reported that renal function could be improved by the use of long-term $\mathrm{C}_{2}$ monitoring ${ }^{1}$ and Delgado et al reported that monitoring with $\mathrm{C}_{2}$ is feasible in terms of preservation of renal function? In the present study, a high level of $\mathrm{C}_{2}$ was offered by our protocol based on $\mathrm{C}_{0}$ and as a result, the Scr level significantly increased at 12 months after transplantation. Mean $\mathrm{C}_{2}$ values $>1,000 \mathrm{ng} / \mathrm{ml}$ at 12 months might not be needed. In terms of preservation of renal function, prudent reduction of the $\mathrm{C}_{2}$ values by dose reduction is recommended. In the present study the number of patients with rejections was too small to decide a target range of $\mathrm{C}_{2}$ for $\mathrm{Cs} A$ to reduce the risk of acute rejection or renal dysfunction.

The development of a LSS for estimation of CsA $\mathrm{AUC}_{0-4 \mathrm{~h}}$ in Japanese heart transplant patients is highly important. We demonstrated that a single-time-point model that included $\mathrm{C}_{2}$ was useful for predicting the full CsA $\mathrm{AUC}_{0-4 \mathrm{~h}}$ in patients treated with $\mathrm{MMF}$ and prednisone concomitantly. Although our study is based on a limited number of patients, it is the first to characterize the pharmacokinetic parameters of CsA in Japanese heart transplant recipients. A more detailed study is necessary to verify the assumption that a single-time-point model that includes $\mathrm{C}_{2}$ is valuable for Japanese heart transplant patients treated with $\mathrm{CsA}$. The study could not present a target range of $\mathrm{C}_{2}$ or $\mathrm{AUC}_{0}-4 \mathrm{~h}$ for $\mathrm{CsA}$ to reduce the risk of acute rejection or renal dysfunction. Further studies should be conducted to investigate the relationship between $\mathrm{CsA} \mathrm{C}_{2}$ or $\mathrm{AUC}_{0-4 \mathrm{~h}}$ and the risk of rejection and renal dysfunction in Japanese heart transplant patients. Furthermore, the optimal therapeutic $\mathrm{C}_{2}$ range for long-term therapy in Japanese heart transplant patients should be investigated.

\section{References}

1. Cantarovich M, Giannetti N, Cecere R. Impact of cyclosporine 2-h level and mycophenolate mofetil dose on clinical outcomes in de novo heart transplant patients receiving anti-thymocyte globulin induction. Clin Transplant 2003; 17: 144-150. 
2. Belitsky P, Dunn S, Johnston A, Levy G. Impact of absorption profiling on efficacy and safety of cyclosporin therapy in transplant recipients. Clin Pharmacokinet 2000; 39: 117-125.

3. Mahalati K, Belitsky P, Sketris I, West K, Panek R. Neoral monitoring by simplified sparse sampling area under the concentration-time curve: Its relationship to acute rejection and cyclosporine nephrotoxicity early after kidney transplantation. Transplantation 1999; 68: $55-62$.

4. Belitsky P, Levy GA, Johnston A. Neoral absorption profiling: An evolution in effectiveness. Transplant Proc 2000; 32: 45S-52S.

5. Cantarovich M, Elstein E, de Varennes B, Barkun JS. Clinical benefit of neoral dose monitoring with cyclosporine 2-hr post-dose levels compared with trough levels in stable heart transplant patients. Transplantation 1999; 68: 1839-1842.

6. Armstrong VW, Oellerich M. New developments in the immunosuppressive drug monitoring of cyclosporine, tacrolimus, and azathioprine. Clin Biochem 2001; 34: 9-16.

7. Cooney GF, Johnston A. Neoral C-2 monitoring in cardiac transplant patients. Transplant Proc 2001; 33: 1572-1575.

8. Cantarovich M, Besner JG, Barkun JS, Elstein E, Loertscher R. Twohour cyclosporine level determination is the appropriate tool to monitor Neoral therapy. Clin Transplant 1998; 12: 243-249.

9. Delgado DH, Rao V, Hamel J, Miriuka S, Cusimano RJ, Ross HJ. Monitoring of cyclosporine 2-hour post-dose levels in heart transplantation: Improvement in clinical outcomes. $J$ Heart Lung Transplant 2005; 24: $1343-1346$.

10. Chou NK, Chen RJ, Ko WJ, Lin HL, Yu SY, Chen YS, et al. Cyclosporine $\mathrm{C} 2$ monitoring is superior to $\mathrm{C} 0$ in predicting acute cellular rejection in heart transplant recipients in Taiwan. Transplant Proc 2004; 36: 2393-2395.

11. Batiuk TD, Pazderka F, Enns J, DeCastro L, Halloran PF. Cyclosporine inhibition of calcineurin activity in human leukocytes in vivo is rapidly reversible. Clin Invest 1995; 96: 1254-1260.
12. Sindhi R, LaVia MF, Paulling E, McMichael J, Burckart G, Shaw S, et al. Stimulated response of peripheral lymphocytes may distinguish cyclosporine effect in renal transplant recipients receiving a cyclosporine + rapamycin regimen. Transplantation 2000; 69: 432-436.

13. Barten MJ, Rahmel A, Garbade J, Richter M, Bittner HB, Dhein S, et al. $\mathrm{C} 0 \mathrm{~h} / \mathrm{C} 2 \mathrm{~h}$ monitoring of the pharmacodynamics of cyclosporin plus mycophenolate mofetil in human heart transplant recipients. Transplant Proc 2005; 37: 1360-1361.

14. Aikawa A, Arai K, Tajima E, Kawamura T, Ogiwara H, Sakai K, et al. Cyclosporine Neoral profiling in Japanese renal transplant recipients. Transplant Proc 2001; 33: 3142-3145.

15. Kitamura S, Kurosawa H, Kondo T, Simizu N, Matuda H, Wada H. Heart and Lung Transplantation Protocols. Tokyo: Medical View Japan; 2003

16. Ray JE, Keogh AM, McLachlan AJ, Akhlaghi F. Cyclosporin C(2) and $\mathrm{C}(0)$ concentration monitoring in stable, long-term heart transplant recipients receiving metabolic inhibitors. J Heart Lung Transplant 2003; 22: 715-722.

17. Arizon del Prado JM, Aumente Rubio MD, Cardenas Aranzana M, Lopez Malo de Molina MD, Segura Saint-Gerons J, Lopez Granados A, et al. New strategies of cyclosporine monitoring in heart transplantation: Initial results. Transplant Proc 2003; 35: 1984-1987.

18. Benowitz NL, Meister W. Pharmacokinetics in patients with cardiac failure. Clin Pharmacokinet 1976; 1: 389-405.

19. Woosley RL, Echt DS, Roden DM. Effects of congestive heart failure on the pharmacokinetics and pharmacodynamics of antiarrhythmic agents. Am J Cardiol 1986; 57: 25B -33B.

20. Kotake T, Takada M, Komamura K, Kamakura S, Miyatake K, Kitakaze M, et al. Heart failure elevates serum levels of cibenzoline in arrhythmic patients. Circ J 2006; 70: 588-592.

21. Ueno K, Tamamura A, Matsumoto K, Komamura K, Kamakura S, Miyatake K, et al. Evaluation of mexiletine clearance in a Japanese population. Ann Pharmacother 2002; 3 241-245. 